Pak. j. sci. ind. res. Ser. A: phys. sci. 2017 60(2) 90-95

\title{
Biosorption of Chromium (VI) and Calculations of Langmuir's and Freundlichs Isotherms
}

\author{
Muhammad Tahir Butt*, Zara Amjad and Rauf Ahmad Khan \\ CEPS, PCSIR Laboratories Complex, Ferozepur Road, Lahore-54600, Pakistan
}

(received June 16, 2016; revised January 25, 2017; accepted January 30, 2017)

\begin{abstract}
In the present study yeast biomass has been successfully used as biosorbent for removal of $\mathrm{Cr}$ from aqueous solution. Yeasts of Saccharomyces cerevisiae are effective biosorbents for heavy metal ions and it can be bought in large quantity at low cost. $S$. cerevisiae can remove toxic metals from aqueous solutions to various levels. This low-cost biosorbent will make the process cost-effective and competitive particularly for environmental applications in detoxifying effluents. Langmuir's and Freundlichs isotherms were also plotted to observe the maximum biosorption of heavy metal chromium (VI).
\end{abstract}

Keywords: heavy metals, biosorption, yeast, wastewater, chromium (VI)

\section{Introduction}

From last few years heavy metal pollution has become most serious environmental threat and discharge of heavy metals into ecosystems has become a matter of concern. These pollutants are introduced into the aquatic systems significantly as a result of various industrial operations (Ahalya et al., 2005). Biosorption is defined as the removal of metal from synthetic solution by biological material (Gadd, 1993). Today heavy metal pollution is one of the most important environmental problems. Many industries produce and discharge wastewater containing different heavy metals into the environment. Thus, metal brings serious environmental pollution, threatening to human health and ecosystem.

Toxic metals such $\mathrm{Hg}, \mathrm{Cr}, \mathrm{Pb}, \mathrm{Cu}, \mathrm{Ni}, \mathrm{Cd}$, (Volesky, 2007) are produced not only by industrial activities, but also mining activities, transport, as well as the spreading of fertilizer and sewage sludge discharge heavy metals into the environment. Methods for removing metal ions from aqueous solutions consist of physical, chemical and biological technologies. Conventional methods for removing metals are reverse osmosis, chemical precipitation, ion exchange, electrodyalysis, ultrafiltration, adsorption on activated carbon, evaporation, etc., (Sarabjeet, 2014; Suryan and Ahluawalia, 2012; Farshid et al., 2008; Sarabjeet and Dinesh, 2007). Hence, the disadvantages like incomplete metal removing, high reagent and energy requirements, generation of sludge or other waste products that require careful disposal has made it imperative for a cost-effective treatment method that is capable of removing heavy metals. Ahalya

\footnotetext{
*Author for correspondence; E-mail: pcsir322@gmail.com
}

et al. (2003) summarized the advantages and disadvantages of those conventional metal removal technologies.

In recent years, applying biotechnologies in controlling and removing metal pollution became hot topic in this field because of its potential application. Alternative process is biosorption, which utilizes various natural materials, including bacteria, fungi, yeast, and algae (Kotrba et al., 2011). These biosorbents have metalsequestering property and can be used to decrease the concentration of heavy metal ions in solution. These natural compounds can sequester dissolved metal ions out of dilute complex solutions with high efficiency (Xie et al., 2003). The major advantages of biosorption over conventional treatment methods include low-cost, high efficiency, minimization of chemical or biological sludge, and regeneration of bio sorbent and possibility of metal recovery (Norton et al., 2004; Volesky, 2001). The complex structure of microorganisms implies that there are many ways for the metal to be taken up by the microbial cell. The biosorption mechanisms are various and not fully understood.

According to the dependence on the cell's metabolism, biosorption mechanisms can be divided into: a) metabolism dependent and b) non metabolism dependent. According to the location where the metal is removed from solution, biosorption can be classified as a) extracellular accumulation, b) cell surface sorption/precipitation) intracellular accumulation (Volesky, 2001). Transport of the metal across the cell membrane yields intracellular accumulation, which is dependent on the cell's metabolism. This kind of biosorption may take place only with viable cells. During non-metabolism biosorption, metal uptake 
is by physicochemical interaction between the metal and the functional groups present on the microbial cell surface (Ahluwalia and Goyal, 2007). This type of mechanism is relatively rapid and can be reversible (Das et al., 2008).

Investigations conducted by several researchers demonstrated that Saccharomyces cerevisiae is capable of accumulating heavy metals such as chromium (VI) (Huang et al., 1990). Yeasts although some species are through the formation of strings of connected budding cells the term "yeast" is often taken as for Saccharomyces cerevisiae (Kotrba et al., 2011). Monascus purpureus, is the most widely used model organisms for genetics and cell biology. Some yeast can find potential application in the field of bioremediation. One such yeast, Yarrowia lipolytica, is known to degrade palm oil mill effluent (Kurtz-man and Fell, 2005; Kurtz-man, 1994) and other hydrocarbons, such as alkanes, fatty acids, fats and oils (Klieger, 2004). It can also tolerate high concentrations of salt (Rao et al., 2004) and is being investigated for its potential as a heavy metal removal (Botstein and Fink, 2011). The procedure of metal removal from aqueous solutions is studied by many researchers (José et al., 2014; Ghasemi et al., 2014; Sage, 2013; Linda and Stanley, 2007). The metabolically independent biosorption of metals by yeast cells occur within several minutes (Babel and Kurniawan, 2003). Heavy metal poisoning could result, and cause allergic skin irritations, dermatitis, irritation to mucous membranes, lung cancer, liver and kidney damage and chrome holes i.e., penetrating ulcers which occur around the fingernails, finger joints, eyelids and occasionally on forearms (Anagnostopoulos et al., 2010).

The aim of this study was to test and compare treated and untreated waste baker's yeast cells ( $S$. cerevisiae) for their capacity to adsorb heavy metals in synthetic solution.

\section{Materials and Methods}

Spectroscopy. The interaction of electromagnetic radiation with matter is known as spectroscopy. Chromium was estimated by Atomic Absorption spectrophotometer model Spectra, 40 Australia.

Chemicals. Merck standard solution, double distilled water was used. All the reagents were of analytical grade and were prepared in double distilled water. For each sample fresh dilutions were used.
Yeast biomass collection. Yeast biomass Saccharomyces cerevisiae was selected for the research work. It was collected from the localities of the PCSIR Laboratories, Lahore. The yeast biomass was initially dried from the moisture, spread on a steel tray, by keeping in an oven at $95{ }^{\circ} \mathrm{C}$ for $30 \mathrm{~min}$. Then this was taken and kept in the 'carbolite furnace' at $200{ }^{\circ} \mathrm{C}$ for about $50 \mathrm{~min}$. After cooling this material was subjected to the sieve analysis.

Chromium standard solution. $25 \mathrm{~mL}$ of stock solution was taken in $250 \mathrm{~mL}$ volumetric flask and volume was raised up to the mark with distilled water. This was 100 ppm chromium solution. From this 100 ppm solution $5,10,15,20,25,30,35,40,45,50 \mathrm{~mL}$ was taken in 10 different $100 \mathrm{~mL}$ volumetric flasks through pipettes and then the volume was made up with distilled water $5,10,15,20,25,30,35,40,45,50$ ppm standard solutions of chromium. These solutions for treatment and calibration were made using the same stock solutions prepared from the 1000 ppm Merck standard solution. Quality control checks were made in this study. The removal of chromium (VI) concentration due to the adsorption was determined by the AA spectra- 40. The percentage of chromium removal due to the bioadsorption was calculated as:

$$
\% \text { Cr removal }=\left[\left(\mathrm{C}_{0}-\mathrm{C}_{\mathrm{e}}\right) / \mathrm{C}_{0}\right] \times 100 \%
$$

where:

$\mathrm{C}_{\mathrm{e}}=$ initial concentration of $\mathrm{Cr}(\mathrm{VI})$ solution,

$\mathrm{C}_{0}=$ equilibrium concentration of $\mathrm{Cr}(\mathrm{VI})$ solution.

Adsorption isotherm procedure. The optimum conditions obtained earlier from the study of metal, i.e. effect of $\mathrm{pH}$, effect of time, effect of biomass quantity and effect of agitation speed at $40{ }^{\circ} \mathrm{C}$ were maintained as constant and only concentration of metal was changed. Some factors which are used in the tables having data of Langmuir and Freundlichs adsorption isotherms, such as:

$\mathrm{V}=$ volume of metal solution used in the experiment (L)

$\mathrm{m}=$ mass of biomass used in the experiment $(\mathrm{g})$

$\mathrm{C}_{\mathrm{e}}=$ initial concentration $(\mathrm{ppm}) ; \mathrm{C}_{0}=$ final concentration (ppm)

$$
\mathrm{q}_{\mathrm{e}}=\mathrm{v}\left(\mathrm{C}_{0}-\mathrm{C}_{\mathrm{e}}\right) / \mathrm{m}
$$

Calibration curve. The instrument was calibrated before analysis and calibration curve was presented in Fig. 1. 


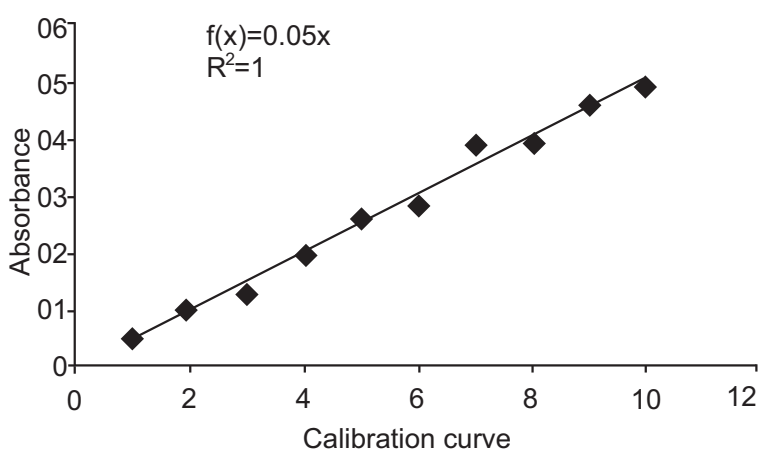

Fig. 1. Cr concentration $(\mathrm{mg} / \mathrm{L})$.

General procedure of biosorption. Yeast biomass (Saccharomyces cerevisiae) $0.2 \mathrm{~g}$ was taken in a 100 $\mathrm{mL}$ conical flask. Then $50 \mathrm{~mL}$ of $5 \mathrm{ppm}$ solution of chromium metal was added. The flask was then shaken at $10-90 \mathrm{~min}$. After shaking, the sample was filtered using Whatmann filter paper No.1 and the filtrate containing residual concentration of chromium (VI) was analysed with AA spectra 40 by comparing these values with the absorption values of standard solutions. Different parameters i.e., effect of $\mathrm{pH}$, effect of time, effect of biomass quantity and effect of agitation speed were studied at room temperature.

\section{Results and Discussion}

Effect of pH. Absorbance was carried out at $\mathrm{pH}$ range of 1-7 and maximum adsorption was in acidic medium at $\mathrm{pH}$ 4. The sorption binding phenomenon was found to be $\mathrm{pH}$ dependent. It was found that the sorption process increases with increasing $\mathrm{pH}$ and is maximum at $\mathrm{pH}$ 4.0. The biosorption in acidic media is greater than the basic media as results shown in Fig. 2. At very low $\mathrm{pH}$ (below 4.0), active sites of biomass for binding of metal ions become less available, so the removal efficiency decreases. The removal efficiency reduced from $\mathrm{pH}$ above 4.0 due to the formation of insoluble chromium hydroxide precipitates that make true sorption studies difficult.

Effect of time. Absorbance was carried out from 10$90 \mathrm{~min}$ and maximum adsorption was at $60 \mathrm{~min}$ as shown in Fig. 3. It means that after 60 min shaking, maximum sites for biosorption are exposed in the solution to bind the metal. Initial removal occurs immediately as metal solution and biomass came in contact, but after 60 min active sites become unavailable and metal needs time to find out more active sites for binding.

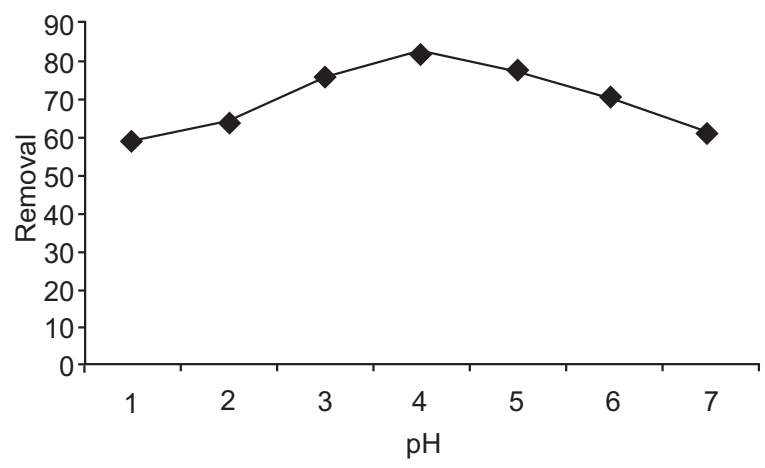

Fig. 2. Different $\mathrm{pH}$ values.

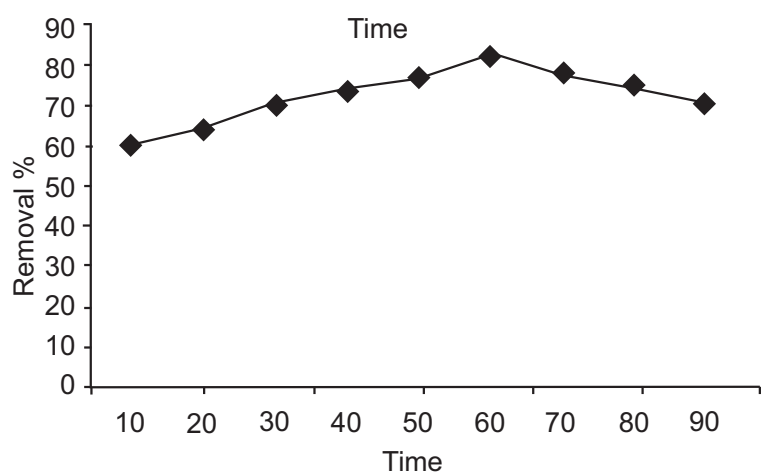

Fig. 3. Time (min).

Effect of biomass quantity. Absorbance was carried out at biomass quantity range of 0.2-1.4 $\mathrm{g}$ and maximum adsorption was at $1.0 \mathrm{~g}$. The sorption of metal increases with increasing biomass quantity which is maximum $1.0 \mathrm{~g}$ as indicated in Fig. 4. The increase in biosorption with the increase in biomass quantity is due to the fact that more active sites are available for metal binding.

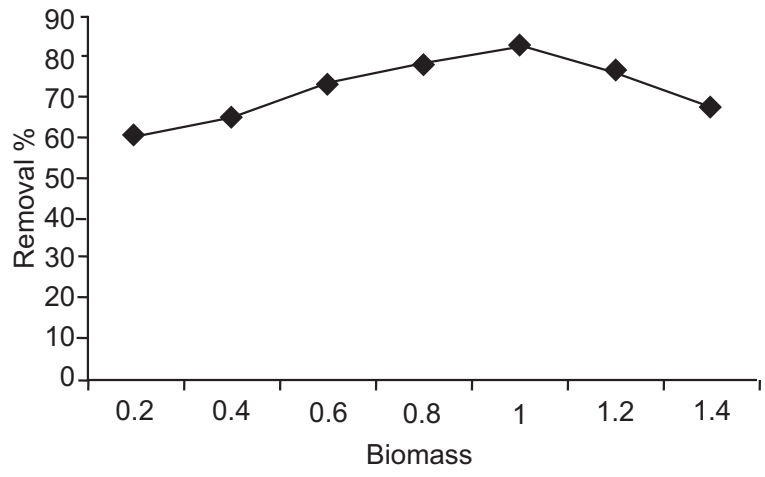

Fig. 4. Biomass (mg). 
Effect of agitation speed. Sorption increases as agitation speed increases. Absorbance was carried out at agitation speed of 50-300 rpm and maximum absorption was at $200 \mathrm{rpm}$. The results of absorbance of various concentrations of chromium are presented in (Fig. 5).

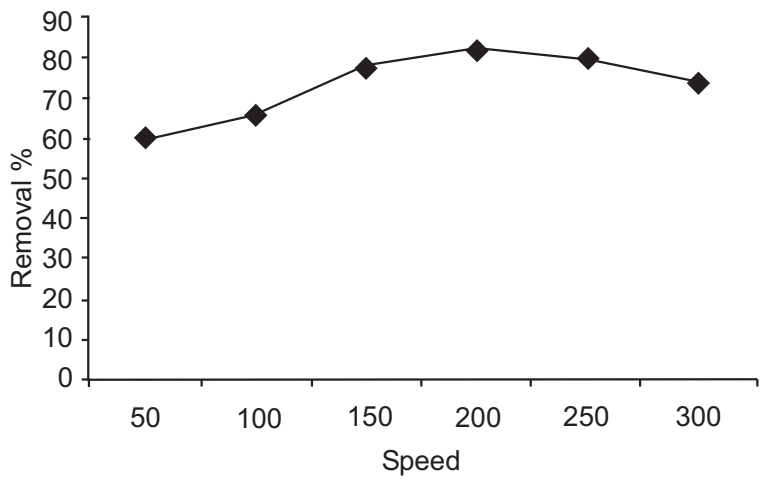

Fig. 5. Agitation speed (rpm).

Biosorption equilibrium isotherms. The sorption of chromium ions were carried out at different initial chromium ion concentrations ranging from $5,10,15$, $20,25,30,35,40,45$ and $50 \mathrm{ppm}$, at optimum $\mathrm{pH} 4$, at $200 \mathrm{rpm}$ with the optimum agitation speed of 200 rpm and at optimum time 60 min while maintaining the adsorbent dose at $1.0 \mathrm{~g}$ of yeast. There are two types of simple sorption isotherm models that are most frequently applied i.e., Langmuir and Freundlichs models.

Langmuir isotherm. The adsorption isotherm, which describes quantitatively the buildup of a layer of molecules on a biosorbent surface as a function of the concentration of the adsorbed material. In a modified form it can also describe a bi-layer deposition and is often expressed as:

$$
\mathrm{q}_{\mathrm{e}}=\mathrm{q}_{\max } \mathrm{b} \mathrm{C}_{\mathrm{e}} /\left(1+\mathrm{b} \mathrm{C}_{\mathrm{e}}\right)
$$

where:

$\mathrm{q}=$ milligram of metal accumulated per gram of bio sorbent,

$\mathrm{C}_{\mathrm{e}}=$ is the residual metal concentration in solution,

$\mathrm{q}_{\max }=$ is the maximum uptake of specific metal cross pounding to specific site saturation and

$\mathrm{b}=$ the ratio of absorption and de absorption rates. This is a theoretical model of monolayer model for adsorption.

$$
1 / \mathrm{q}_{\mathrm{e}}=1 / \mathrm{b} \mathrm{q}_{\max } \mathrm{C}_{\mathrm{e}}+1 / \mathrm{q}_{\max }
$$

The Langmuir constants $\mathrm{q}$ max and $\mathrm{b}$ can be evaluated from the slope (y) and intercept (x) linear equation.

Freundlichs isotherm. Freundlichs presented an empirical adsorption isotherm for non-ideal systems. The Freundlichs isotherm is exponential in the form and often represents an initial surface adsorption followed by a condensation effect resulting from extremely strong solute-solute interaction. It is expressed as:

$$
\text { Freundlichs isotherm: } \mathrm{q}_{\mathrm{e}}=\mathrm{K}_{\mathrm{f}} \mathrm{C}_{\mathrm{e}}{ }^{1 / \mathrm{n}}
$$

where:

$\mathrm{k}$ and $\mathrm{n}$ are constants. These models can be applied at constant $\mathrm{pH}$ and can be used for modeling of biosorption of equilibrium at the presence of one metal. This equation is conveniently used in the linear form by taking the logarithmic of both sides which can be used for the linearization of experimental data:

$$
\log \mathrm{q}_{\mathrm{e}}=\log \mathrm{K}_{\mathrm{f}}+1 / \mathrm{n} \log \mathrm{C}_{\mathrm{e}}
$$

The constants of Freundlichs isotherm $\mathrm{K}_{\mathrm{f}}$ and $\mathrm{n}$ can be determined from the slope (y) and the intercept (x) of linear equation.

Results of Langmuir and Freundlichs isotherms. The constants of Langmuir and Freundlichs isotherms for chromium metal are given below in Table 1-2.

Yeast is a promising biosorbent for heavy metals and has come into notice of researchers due to its unique nature and average uptake capacity of metals. A comparative study of biosorbent was carried out by

Table 1. Constants of the isotherms

\begin{tabular}{|c|c|c|c|c|}
\hline \multirow[t]{2}{*}{ Metal } & \multicolumn{2}{|l|}{ Langmuir data } & \multicolumn{2}{|l|}{ Freundlichs data } \\
\hline & Linear equation & $\mathrm{R}^{2}$ & Linear equation & $\mathrm{R}^{2}$ \\
\hline $\mathrm{Cr}(\mathrm{VI})$ & $\begin{array}{l}y=4.181 x+ \\
0.4964\end{array}$ & 0.9128 & $\begin{array}{l}y=0.917 x- \\
0.7646\end{array}$ & 0.887 \\
\hline
\end{tabular}

\begin{tabular}{llllll}
\hline \hline Metal & \multicolumn{2}{l}{ Langmuir constants } & & \multicolumn{2}{l}{ Freundlichs constants } \\
\cline { 2 - 3 } \cline { 5 - 6 } & $\mathrm{q}_{\max }(\mathrm{mg} / \mathrm{g})$ & $\mathrm{b}(\mathrm{L} / \mathrm{mg})$ & & $\mathrm{K}_{\mathrm{f}}$ & $\mathrm{n}$ \\
\hline $\mathrm{Cr}(\mathrm{VI})$ & 2.014 & 0.119 & & 1.127 & 1.090 \\
\hline \hline
\end{tabular}

Table 2. Linear regression data for Langmuir and Freundlichs isotherms

$\mathrm{R}^{2}=$ shows correlation or linear relationship while $\mathrm{y}$ and $\mathrm{x}$ indicate the slope and intercept of the linear equations, respectively. 
Bakkaloglu et al. (1998). They compared the removal efficiency of $\mathrm{Zn}, \mathrm{Cu}$ and $\mathrm{Ni}$ ions on sedimentation, biosorption and desorption. The results showed that $S$. cerevisiae has average uptake capacity of one or multi metals bio absorption system. The results of this study show that maximum absorption of $\mathrm{Cr}$ (VI) was at pH4, with $200 \mathrm{rpm}$ and $60 \mathrm{~min}$ time at one gram of biomass material $S$. cerevisiae. The adsorption equibiliuram results were modeled using Langmuir and Freundlichs isotherm and experimental data were well fitted to the Freundlichs equation. Experiments were made in batches to study the effects of Cr (VI). Experimental and kinetics data was expressed by Langmuir effect on the adsorption rate. The potential to remove $\mathrm{Cr}$ (VI) from synthetic solution Bengal gram was investigated by Ahalya et al. (2005). The Cr (VI) removal from synthetic solution was $82 \%$. The Freundlichs

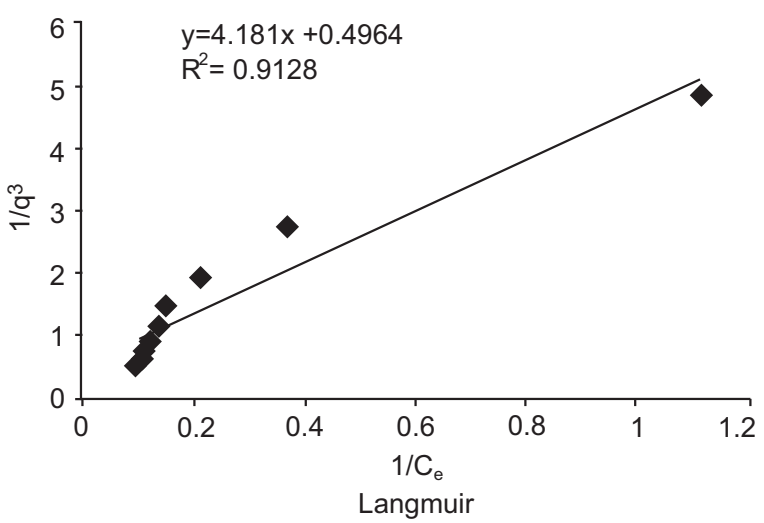

Fig. 6. Initial concentration of chromium (Langmuir isotherm).

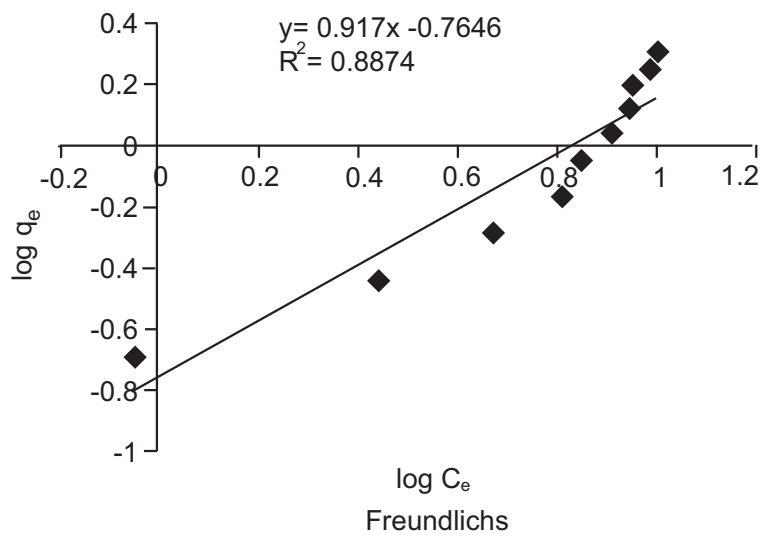

Fig. 7. Chromium concentration after treatment (Freundlichs isotherm). isotherm and Langmuir isotherm showed the similar results as presented in Fig. 6-7.

\section{Conclusion}

The cost effective technology that can be applied on large scale in decontamination of industrial effluents was studied by using yeast, Saccaromyces cerevisiae as a biosorbent. After removal of metals from wastewater, metals can be recovered and matter can be regenerated for further use. Two adsorption models, the Langmuir model and the Freundlichs equation were applied to the experimental data obtained from yeast biomass and correlations results were found similar for these models. New low-cost technologies are necessary to remove heavy metals in the environment to limit values.

\section{References}

Ahalya, N., Kanamadi, R.D., Ramachandra, T.V. 2005. Biosorption of chromium (VI) from aqueous solutions by husk of Bengal gram (Cicer arientinum, Electronic Journal of Bioethanol, 8: 258-264.

Ahalya, N., Ramachandra, T.V., Kanamadi, R.D. 2003. Bio sorption of heavy metals. Research Journal of Chemistry and Environment, 7: 71-79.

Ahluwalia, S.S., Goyal, D. 2007. Microbial and plant derived biomass for removal of heavy metals from wastewater. Bioresource Technology, 98: 22432257.

Anagnostopoulos, V.A., Symeopoulos, B.D., Soupioni, M.J. 2010. Effect of growth conditions on bio sorption of cadmium and copper by yeast cells. Global NEST Journal, 12: 288-295.

Babel, S., Kurniawan, T.A. 2003. Low-cost adsorbents for heavy metal uptake from contaminated water: a review. Journal of Hazard Material, 97: 219-243.

Bakkaloglu, I., Butter, T.J., Evison, L.M., Holland, F.S., Hancock, I.C. 1998. Screening of various types biomass for removal and recovery of heavy metals ( $\mathrm{Zn}, \mathrm{Cu}$, and $\mathrm{Ni}$ ) by bio sorption, sedimentation and desorption. Water Science \& Technology, 38: 269-277.

Botstein, D., Fink, G. R. 2011. Yeast: an experimental organism for $21^{\text {st }}$ Century biology. Genetics, 189: 695-70.

Das, N., Vimala, R., Karthika, P. 2008. Biosorption of heavy metals-an overview. Indian Journal of Biotechnology, 7: 159-1694.

Farshid, G., Habibollah, Y., Seyed, M.G., Ali, A.Z., Mahlihe, A., Ali. 2008. Application of response 
surface methodology for optimization of cadmium bio sorption in an aqueous solution by Saccharomyces cerevisiae. Chemical Engineering Journal, 145: 267-275.

Gadd, G.M. 1993. Interactions of fungi with toxic metals, Phytologist, 124: 25-60.

Ghasemi, M., Naushad, M., Ghasemi, N., Khosravifard, Y. 2014. A novel agricultural waste based adsorbent for the removal of $\mathrm{Pb}$ (II) from aqueous solution: kinetics, equilibrium and thermodynamic studies. Journal of Industrial and Engineering Chemistry, 20: 454-461.

Huang, C.P., More-hart, A. 2014. Bio sorption of hexavalent chromium from aqueous medium with Opuntia biomass. Scientific World Journal, 10: 1155.

Huang, C.P., Huang, C.P., More-hart, A. 1990. The removal of $\mathrm{Cu}$ (II) from dilute aqueous solutions by Saccharomyces cerevisiae. Water Research, 4: 433-439.

José, A., Fernandez, L., José, M., Angosto, Maria, D.A. 2014. Biosorption of hexavalent chromium from aqueous medium with Opuntia biomass. Scienctific World Journal, 10: 1155.

Kotrba, P., Mock-ova, M., Urbane-k, V. (eds). 2011. Microbial Biosorption of Metals, pp. 1-6, Springer, The Netherlands.

Kurtz-man, C.P., Fell, J.W. 2005. Biodiversity and Eco Physiology of Yeasts. The Yeast Handbook, Gabor P, de-la-Rosa C. L. (eds.), pp. 11-30, Berlin, Springer, The Netherlands.

Kurtz-man, C.P. 1994. Molecular taxonomy of the yeasts. Yeast, 10: 1727-1740.
Linda, Y., Stanley, P.C. 2007. Technology of Bread Making. pp. 79, Berlin Springer, The Netherlands.

Norton, L., Baskran, K., McKenzie, K. 2004. Biosorption of zinc from aqueous solution using biosolids. Advances in Environmental Research, 8: 629-635.

Rao, R.S., Prakasham, R.S., Prasad, K.K., Rajesh-am, S., Sarma, P.N., Rao, L. 2004. Xylitol production by Candida sp. parameter optimization using Taguchi approach. Process Biochemistry, 39: 951-956.

Sag, K. 2013. What is the Difference between Brewer's Yeast \& Baker's Yeast. Livestrong.com.retrieved 14 May, 2013.

Sarabjeet, S.A. 2014. Microbial removal of hexavalent chromium and scale up potential. International Journal of Current Microbiological Applied Science, 3: 383-398.

Sarabjeet, S.A., Dinesh, G. 2007. Microbial and plant derived biomass for removal of heavy metals from wastewater. Review Bio resource Technology, 98: 2243-2257.

Suryan, S., Ahluawalia, S.S. 2012. Biosorption of heavy metals by paper mill waste from aqueous solution. International Journal of Environmental Sciences, 2: 1331-1343.

Volesky, B. 2007. Biosorption and metals. Water Research, 41: 4017-4029.

Volesky, B. 2001. Detoxification of metal-bearing effluents: bio sorption for the next century, Hydrometallurgy, 59: 203-216.

Xie, D.D., Liu, Y.Y., Wu, C.L., Fu, J.K., Xue, R. 2003. Studies on bio sorption of $\mathrm{Pd} 2+$ by the immobilized Saccharomyces cerevisiae waste biomass. Microbiology, 30: 29-34. 